\title{
Düzenli Pilates Egzersizi Yapan Kadınlar ile Sedanter Kadınlarda Y Denge Testi Performansının Karşılaştırılması
}

\author{
Comparison of Y Balance Test Performance in Women with Regular Pilates Exercise and Sedentary Women \\ Bahar Ateş ${ }^{1}$ (D) , Mehmet Ali Öztürk² (D) \\ 1 Uşak Üniversitesi, Spor Bilimleri Fakültesi, Uşak/Türkiye \\ 2 Karabük Üniversitesi, Hasan Doğan Beden Eğitimi ve Spor Yüksekokulu, Karabük/Türkiye
}

\section{ÖzeT}

AMAÇ: Bu çalışma ile düzenli olarak pilates egzersizi yapan kadınlar ile düzenli bir egzersiz programına katılmayan kadınların Y Denge Testi (YBT) performanslarının karşılaştırılması amaçlandı.

GEREÇ VE YÖNTEM: Çalışmada, en az 1 yıl düzenli olarak pilates egzersizi yapan 28 kadın, Pilates Grubunu (PG) ve düzenli olarak bir egzersiz programına katılmayan 34 kadın ise Kontrol Grubunu (KG) oluşturdu. Her katılımcının yaş, boy, kilo, baskın bacak ve bacak uzunlukları ölçümleri alındı. Y Denge Test (YBT) platformu kullanılarak katılımcıların, anterior (ANT), posteromedial (PM) ve posteriolateral (PM) olmak üzere 3 yönde uzanma mesafeleri ölçüldü. Elde edilen puanların her yön için (ANT, PM ve PL) ortalama değerleri ve bacak uzunluk değerlerine göre normalize değerlerine ulaşıldı ve ANT, PM ve PL puanların ortalaması alınarak ortalama puan değeri (COMP) hesaplandı..

BULGULAR: PG'nin ANT, PM ve PL yönlerde KG'ye oranla daha yüksek puanlara sahip oldukları belirlendi. Bu farklılıklar özellikle ANT ve PM yönlerde $p<0,005$ düzeyinde istatistiksel açından anlamlılık oluşturdu. COMP puanlarında PG'nin KG'ye oranla daha yüksek puanlara sahip olduğu ancak sadece sağ bacak uzanma değerinde bu farkın anlamlılı oluşturduğu gözlemlendi. Sağ ve sol bacak uzanma değerleri ortalama farklarının ise KG'de PG'ye oranla daha fazla olduğu görüldü. Özellikle PM yönünde 5,2 \pm 4,9 gibi yüksek bir değer gözlemlendi..

SONUÇ: Sonuç olarak, düzenli yapılan pilates egzersizlerinin kadınlarda dinamik postüral kontrol üzerine olumlu etkileri olduğu söylenebilir. Ayrıca, elde edilen veriler ve ilgili literatür kapsamında, spor yapan kadınlarda uygulanan YBT çalışmalarının düzenli egzersiz yapmayan kadınlarda da egzersiz programlarına katılım öncesi tarama, yaralanma tahmini gibi amaçlarla uygulanması önerilmektedir.

Anahtar Kelimeler: kadınlar, dinamik postüral kontrol, tarama

\section{ABSTRACT}

OBJECTIVE: The aim of this study is to compare the performances of " $Y$ Balance Test" of women who perform pilates exercises regularly and those who do not regularly exercise..

MATERIALS AND METHODS: In the study, 28 women who regularly performed pilates at least one year, the Pilates Group (PG) and 34 women who did not participate in an exercise program regularly formed the Control Group (CG). Age, height, weight, dominant leg and limb lengths of each participant were measured. Y BalanceTest (YBT) platform was used to measure the distance of the participants in 3 directions, anterior (ANT), posteromedial (PM) and posteriolateral (PL). Mean values for each direction (ANT, PM and $P L)$ and normalized values for limb length values were calculated. Then, the average score value (COMP) was calculated by taking the average of ANT, PM and PL scores.

RESULTS: PG had higher scores in ANT, PM, and PL than CG. These differences were statistically significant at the $p<0.005$ level especially in the ANT and PM directions. In the COMP scores, it was observed that PG had higher scores than CG, but this difference was significant only for right limb extension. The mean difference between right and left leg extension values was found to be higher than that of PG. In particular, a high value of $5.2 \pm 4.9$ was observed in the PM direction.

CONCLUSION: In conclusion, it can be said that regular pilates exercises have positive effects on dynamic postural control in women. In addition, the data obtained and related literature; It is recommended that the YBT studies performed in women who do sports do not apply to the exercise programs in the women who do not exercise regularly.

Key Words: women, dynamic postural control, screening

Yazışma Adresi/Address for Correspondence: : Bahar Ateş, Uşak Üniversitesi Spor Bilimleri Fakültesi, Uşak/Türkiye

E-Posta/E-Mail: atesbhr@gmail.com || Tel: +90 5303033594

Received/Geliş Tarihi: 8 Oca 2019|| Accepted/Kabul Tarihi: 22 Şub 2019

Bu Eser Creative Commons Atıf-Gayriticari 4.0 Uluslararası Lisansı İle Lisanslanmıştır. This work is licensed under a Creative Commons

Attribution-NonCommercial 4.0 International License (CC BY-NC 4.0). 


\section{Giriş}

Son yıllarda, denge yeteneğinin yaşam kalitesini ve atletik performansı artırmak için son derece gerekli bir parametre olduğu belirtilmektedir. Aynı zamanda denge performansındaki bozulmaların sakatlıklar için de bir risk faktörü oluşturduğu bilinmektedir (1, 3). Yaralanma risklerini ve bir yaralanmaya müdahaleden sonra iyileşme süresini değerlendirmek için sıklıkla postüral kontrol değerlendirmeleri (4), geliştirilmesi ve bu gelişim için yapılması gereken egzersizleri içeren çok fazla çalışma bulunmaktadır $(1,5,6,7,8)$. Yapılan çalışmalar, dinamik postüral kontrol performansının arttırılması ile alt ekstremite sakatlık risklerinin önlenebileceğini göstermiştir $(9,10)$. Ayrıca Huxham ver ark. insanın denge sağlamadaki yeteneğinin, diğer motor sistemlerin gelişmesinde de belirleyici bir faktör olacağını belirtmiştir (11).

Dinamik dengenin; tüm yaşlarda önemli bir beceri olduğu düşünülmektedir ve dinamik hareketlerin kontrolü gerektiren normal günlük görevler için de gerekli olduğu belirtilmektedir $(3,11)$. Dinamik postüral kontrol, bir destek temeli etrafında istemli hareket seviyelerini kapsamaktadır (4). Kas dengesizliği, azalmış kore stabilitesi ve anormal hareket modelleri olan bireylerde, kullanılacak olan bir tarama sisteminin, gelecekte oluşabilecek sakatlıkların önlenmesinde faydalı olabileceği belirtilmektedir (12). Klinik olarak yaralanma tahmini için kullanılan tarama araçları; Fonksiyonel Hareket Analizi (FMS) ve Y Denge Testi (YBT)'dir. YBT sağ ve sol ayak üzerinde, anterior (ANT) posteriolateral $(P L)$ ve posteriomedial $(P M)$ olmak üzere üç farklı yöndeki dinamik dengeyi ölçmektedir ve kuvvet, propriyosepsiyon ve esneklik gerektirmektedir. Ölçümlerin analizinde her iki bacağın ulaştığı mesafeler karşılaştırıldığında, her yön için 4 cm'den daha az fark olması beklenmektedir. Lehr ve ark. üniversiteli sporcularda yaptıkları çalışmada, YBT'nin ortalama erişim performansına bağlı gelecekti alt ekstremite yaralanmalarının tahmin edilebileceğini bildirmişlerdir (13). Plisky ve ark. liseli basketbolcularda yaptıkları çalışmalarında, 4 cm'den büyük anterior sağ / sol uzanma mesafesi farkının alt ekstremite yaralanmasını olasılığı 2,5 kat daha fazla olduğunu tespit etmişlerdir (14). Sportif egzersizlerin branşa özgü postüral adaptasyonları geliştirdiği belirtilmektedir (15). Uzmanlar bu sistem üzerinde ortak bir kanıt olmasa da yapılan çalışmalar hem duyusal hem de motor sistemlerdeki değişiklerin denge performansını etkilediğini göstermektedir (16).
Pilates altı temel prensibe (konsantrasyon, hareketlerin tüm yönlerinin kontrolü, merkezleme, akıcı hareket, kesinlik ve nefes alma) dayanarak kusursuz bir zihin ve beden dengesi geliştirme ve korumayı hedefleyen, jimnastik, dövüş sanatları, yoga ve dansın hareket tarzları ve felsefesinin birleşimi olan bir egzersiz türüdür $(17,18)$. Pilates egzersizleri ile fiziksel açıdan kas kuvveti ve dayanıklıı̆ı̆n artması, esneklik ve dengenin geliştirilmesi amaçlanmaktadır (19). Pilates egzersizleri koşma, sıçrama gibi aktiviteler olmadan oturma, ayakta durma gibi statik egzersiz programları ile yapılmaktadır (20). Aynı zamanda pilates egzersiz programları arasında germe, kuvvet, odaklanma, nefes egzersizleri gibi çeşitli aktiviteler yer almaktadır.

Literatür incelendiğinde, sağlıklı genç yetişkinlerde özellikle egzersiz yapmayan bireylerde, dinamik postüral kontrolün değerlendirilmesine ilişkin çalışmalar çok azdır. Bu kapsamdan yola çıkarak, bu çalışmanın amacı, düzenli olarak pilates egzersizi yapan ve düzenli bir egzersiz programına katılmayan kadınlarda YBT performans değerinin karşılaştırılmasıdır. Yapılan bu güncel çalışmada, düzenli olarak pilates yapan grupta, YBT uzanma ve ortalama performans değerlerinin daha iyi olacağı hipotezi varsayılmıştır.

\section{GEREÇ VE YÖNTEM}

Çalışmaya, özel bir spor salonunda düzenli olarak en az 1 yıl mat ve reformerdan oluşan pilates egzersizleri yapan, 28 kadın ve düzenli olarak bir egzersiz programına katılmamış 34 kadın dahil edildi. Katılımcılara gönüllü onam formu imzalatıldı ve çalışma Helsinki Deklarasyonu ilkelerince yürütüldü. Çalışmaya katılım kriterleri; bilinen bir nörolojik, mental, ortopedik, vestibüler ve sistemik gibi hastalık olmaması, denge testini tamamlamayı engelleyen herhangi bir problemin olmaması, çalışmadan önce şiddetli bir egzersiz yapılmamış olması ve gönüllü olunması olarak belirlendi. Her katılımcı için kişisel bilgiler, boy, kilo ölçümleri alınıp kaydedildikten sonra, spor kıyafetiyle 5 dakika hafif koşu ile ısındıktan sonra ve dinamik hareketleri içeren esnetme yaptıktan sonra YBT her iki bacak için uygulandı.

\section{Veri Toplama Yöntemi}

Boy ve vücut ağırlı̆̆; katılımcılar 20 grama kadar hassas bir kantarda (Angel marka) çıplak ayak ve sadece şort ve tişört 
giydirilerek tartıldı. Uzunluk (boy) ölçümleri Holtain marka kayan kaliper ile ayakta dik pozisyonda dururken skalanın üzerinde kayan kaliper başlarının üzerine dokunacak şekilde ayarlandı ve uzunluk $1 \mathrm{~mm}$ hassasiyetle okundu. Vücut Kitle İndeksi (VKi); vücut ağırlığı (kg) / boy $(\mathrm{m})^{2}$ formülü kullanılarak tespit edildi.

Y Denge Testi (YBT); Sporcuların denge parametrelerini ölçmek için "Y BalanceTest" platformu kullanıldı. Her katılımcının bacak uzunluğu; santimetre olarak supin pozisyonunda çift taraflı bir şekilde anterior superioriliak noktadan medial malleolün distal kısmına kadar ölçülerek kaydedildi. ANT uzanma katılımcının merkezdeki ayak parmak ucundan, PL ile PM ise ayak topuğundan uzanabildiği en uzak nokta arasındaki mesafe olarak test edildi. Test, katılımcıların bir ayakları kesişme noktasında iken, serbest olan ayaklarını maksimum uzaklığa uzatabilmeleri için ayakkabısız olmalarını gerektirmektedir. Deneme süresince, katılımcılardan ellerini iliyak üzerinde topuklarını ise zemin üzerinde tutmaları ve uzanma ayağının parmak ucuyla en uzak noktaya hafif bir dokunuş yapmaları istendi. Ölçümden önce testin nasıl uygulanacağı ile ilgili deneyimli araştırmacı tarafından kısa bir gösterim yapıldı ve katılımcıların en az 6 kere, her yöne, deneme yapmaları sağlandı (12). Test denemelerinin tamamlanmasından sonra, her katılımcıya 2 dakikalık bir dinlenme süresi verildi ve daha sonra her yönde 3 test denemesi yapıldı. Ölçüm sırasında; katılımcılar vücut ağırlığını uzanma ayağına aktardıklarında, duruş ayağının topuğunu zeminden ayırdığında, ya da ellerini kalçadan ayırdığında deneme kabul edilmedi ve katılımcının bir daha hata yapmaması için sözlü olarak bilgilendirildikten sonra deneme tekrarlandı. Bütün uzanma mesafeleri santimetre cinsinden kaydedildi. Veriler elde edildikten sonra, her yön için en iyi uzanma puanları bacak uzunluk değerlerine göre "en iyi uzanma mesafesi/bacak uzunluğu) x $100=\%$ Maks" formülü kullanılarak normalize edildi (22). Normalize edilen puanlar duruş bacak uzunluğunun (\%LL) bir yüzdesi olarak gösterildi. Normalize edilmiş ANT, PL ve PM puanlarının ortalaması alınarak ortalama puan değeri (COMP) bulundu.

\section{İstatistiksel Değerlendirme}

Çalışmada elde edilen veriler, SPSS 23 istatistiksel paket programında analiz edildi. Çalışmaya katılan tüm katılımcılar yaş, boy, vücut ağırlığı, ANT, PL ve PM değerlerinin ortalamaları, standart sapma değerleri hesaplanarak yorumlandı. Verilerin normal dağılıma uygun olup olmadığını ortaya koymak amacıyla skewness ve kurtosis ve Shapiro-Wilk değerlerine bakıldı. Normallik testi sonucunda verilerin dağılımının normal dağıldığı tespit edildi ve grupların ikili olması nedeniyle gruplar arası ANT, $\mathrm{PL}$, $\mathrm{PM}$ ve COMP skorları arasındaki farklılıkların karşılaştırılmasında parametrik testlerden Bağımsız Örneklem-T Testi kullanıldı. Bacak uzunluğu ve vücut kitle indeksi (BKi) ile COMP uzanma mesafeleri arasındaki ilişki, Pearson Korelasyon Analizi ile değerlendirildi. Çalışmada güven aralığı (Cl) \%95 ve anlamlılık seviyesi $p<0,05$ olarak belirlendi.

\section{BULGULAR}

Katıımcıların yaş, boy, kilo, vücut kitle indeksi (VKi) ve bacak uzunlukları ortalama değerleri Tablo 1'de gösterilmektedir. Bacak uzunlukları ve VKi hariç, yaş, boy ve kilo değerleri PG ve KG grubunda benzer olarak tespit edildi. Tercih edilen bacak açısından bakıldığında, PG katılımcılarından sadece 2 $(\% 7,1)$ kişinin baskın bacağının sol bacak olduğu buna mukabil KG katılımcılarından toplam $10(\% 29,4)$ kişinin baskın bacağının sol bacak olduğu tespit edildi.

Tablo 1. Araştırmada yer alan katılımcıların demografik özellikleri

\begin{tabular}{|c|c|c|c|}
\hline & $\begin{array}{c}\text { PG } \\
(n=28) \\
(\bar{x} \pm S S)\end{array}$ & $\begin{array}{c}\text { KG } \\
(n=34) \\
(x \pm S S)\end{array}$ & $\mathbf{p}$ \\
\hline Yaş (yıl) & $34,8 \pm 7,3$ & $31,6 \pm 7,8$ & 0,108 \\
\hline Boy $(\mathrm{cm})$ & $166,4 \pm 5,4$ & $163,5 \pm 7,4$ & 0,092 \\
\hline Kilo (kg) & $56,6 \pm 4,2$ & $61,0 \pm 12,3$ & 0,060 \\
\hline Bacak Uzunluğu (cm) & $89,7 \pm 3,9$ & $86,4 \pm 4,6$ & $0,004 *$ \\
\hline VKi $\left(\mathrm{kg} / \mathrm{m}^{2}\right)$ & $20,4 \pm 1,3$ & $23,1 \pm 4,7$ & $0,004^{*}$ \\
\hline Baskın Bacak & $\mathrm{N}(\%)$ & $\mathrm{N}(\%)$ & \\
\hline Sağ Bacak & $26(92,9)$ & $24(70,6)$ & \\
\hline Sol Bacak & $2(7,1)$ & $10(29,4)$ & \\
\hline
\end{tabular}

SS = Standart Sapma; VKi = Vücut Kitle Indeksi; * $p<0,05 ; P G=$ Pilates Grubu; $K G=$ Kontrol Grubu; $\overline{x=}$ Ortalama Puan

YBT'nin uzanma mesafelerinin analizinde, ANT, PM ve COMP uzanma mesafelerinde, sağ ve sol bacak ortalama değerlerinde PG ve KG arasında anlamlı istatistiksel farka rastlandı (ANT [sağ bacak: $p=0,000$, sol bacak: $p=0,000$, toplam: $p=0,000], P M$ [sağ bacak: $p=0,000$, sol bacak: $p=0,027$, toplam: $p=0,003])$. PL uzanma mesafesinin, PG grubunda KG grubuna göre sağ bacak, sol bacak ve toplamda daha yüksek olmasına rağmen bu farklılıkların iki grup arasında istatistiksel açıdan anlamlılık oluşturmadığı görüldü $(p<0,05)$. Sağ ve sol bacak ortalama farklarının ANT, $P M$ ve $P L$ yönlerin tümünde, $K G^{\prime}$ de daha yüksek olduğu 
gözlemlendi ancak PG ile karşılaştırıldığında herhangi bir anlamlılık tespit edilmedi $(p<0,05)$ (Tablo 2$)$.

Tablo 2. Katılımcıların ANT, $P M$ ve $P L$ puanlarının karşılaştırılması

\begin{tabular}{|c|c|c|c|c|}
\hline & $\begin{array}{c}P G \\
(n=28) \\
(x \pm S S)\end{array}$ & $\begin{array}{c}\text { KG } \\
(n=34) \\
(\bar{x} \pm S S)\end{array}$ & $\mathbf{p}$ & $\begin{array}{l}\text { OPF } \pm \text { SS } \\
{[\% 95 \mathrm{CI}]}\end{array}$ \\
\hline \multicolumn{5}{|c|}{ Anterior uzanma mesafesi (cm) } \\
\hline Sağ Bacak & $55,8 \pm 4$ & $48,0 \pm 5,4$ & 0,000 * & $7,7 \pm 1,2[5,2-10,2]$ \\
\hline Sol Bacak & $54,8 \pm 6,6$ & $50,4 \pm 5,4$ & 0,001 * & $4,4 \pm 1,2[1,9-6,9]$ \\
\hline Toplam & $55,3 \pm 3,6$ & $49,2 \pm 5,2$ & $0,000 *$ & $6,1 \pm 1,1[3,7-8,4]$ \\
\hline OF & $2,6 \pm 2$ & $3 \pm 2,3$ & 0,431 & $-0,4 \pm 0,5[-1,5-0,6]$ \\
\hline \multicolumn{5}{|c|}{ Posteromedial uzanma mesafesi $(\mathrm{cm})$} \\
\hline Sağ Bacak & $92,2 \pm 5,5$ & $82,4 \pm 12,1$ & $0,000^{*}$ & $9,7 \pm 2,4[4,7-14,7]$ \\
\hline Sol Bacak & $90,5 \pm 7,3$ & $83,8 \pm 14$ & $0,027 *$ & $6,6 \pm 2,9[0,7-12,5]$ \\
\hline Toplam & $91,3 \pm 6$ & $83,1 \pm 12,6$ & $0,003^{*}$ & $8,2 \pm 2,6[3,0-13,4]$ \\
\hline OF & $3,9 \pm 3,2$ & $5,2 \pm 4,9$ & 0,225 & $-1,3 \pm 1,0[-3,5-0,8]$ \\
\hline \multicolumn{5}{|c|}{ Posteriolateral uzanma mesafesi $(\mathrm{cm})$} \\
\hline Sağ Bacak & $90,0 \pm 7,8$ & $84,6 \pm 13,3$ & 0,061 & $5,4 \pm 2,8[-0,2-11,2]$ \\
\hline Sol Bacak & $89,6 \pm 9$ & $85,2 \pm 13,2$ & 0,139 & $4,4 \pm 2,9[-1,4-10,2]$ \\
\hline Toplam & $89,8 \pm 8,2$ & $84,9 \pm 13$ & 0,088 & $4,9 \pm 2,8[-0,7-10,6]$ \\
\hline OF & $2,9 \pm 3,3$ & $3,6 \pm 3$ & 0,346 & $-0,7 \pm-0,9[-2,1-0,7]$ \\
\hline
\end{tabular}

$O F=$ Sağ ve sol bacak ortalama farkl; OPF= Pilates grubu ve kontrol grubu ortalama puan farklarl; SS=Standart Sapma; * $p<0,05 ; C l=$ Güven Aralığl; $P G=$ Pilates Grubu; $K G=$ Kontrol Grubu; $x \equiv$ Ortalama Puan

Katılımcıların bacak uzunluğuna göre normalize COMP puanlarına göre değerlendirildiği Tablo 3 incelendiğinde, sağ bacak uzanma değerinde ( $p=0,009)$ PG lehine anlamlı farklılık görüldü $(p<0,05)$. Sol bacak ve toplam puanlarda gruplar arasında anlamlılık tespit edilmedi $(p>0,05)$.

Tablo 3. Katılımcıların sağ bacak, sol bacak ve toplam COMP normalize puanlarının karşılaştırılması

\begin{tabular}{|c|c|c|c|c|}
\hline COMP Puanları & $\begin{array}{c}\text { PG } \\
(n=28) \\
(x \pm S S)\end{array}$ & $\begin{array}{c}\text { KG } \\
(n=34) \\
(x \pm S S)\end{array}$ & $\mathbf{p}$ & $\begin{array}{c}\text { OPF } \pm \\
\text { SS [\%95 CI] }\end{array}$ \\
\hline Sağ Bacak & $88,5 \% \pm 5,7 \%$ & $82,9 \% \pm 9,7 \%$ & 0,009 * & $\begin{array}{c}5,6 \% \pm 2,0 \%[1,4- \\
9,7 \%]\end{array}$ \\
\hline Sol Bacak & $96,4 \% \pm 5,5 \%$ & $95,4 \% \pm 9,5 \%$ & 0,638 & $\begin{array}{c}4,4 \% \pm 1,2 \%[1,9- \\
6,9 \%]\end{array}$ \\
\hline Toplam & $92,4 \% \pm 5,2 \%$ & $89,1 \% \pm 9,2 \%$ & 0,1 & $\begin{array}{c}6,1 \% \pm 1,1 \%[3,7- \\
8,4 \%]\end{array}$ \\
\hline
\end{tabular}

$O P F=$ Pilates grubu ve kontrol grubu ortalama puan farklarl; SS= Standart Sapma; * $p<0,05 ; \mathrm{Cl}=$ Güven Aralığl; \% = Bacak uzunluğuna göre normalize edilmiş uzanma değerleri; $P G=$ Pilates Grubu; $K G=$ Kontrol Grubu; $x=$ Ortalama Puan

Bacak uzunluğu ve VKi ile COMP uzanma mesafesi arasında ise anlamlı bir ilişkiye rastlanılmadı (sırasıyla: $r=0.16, p=$ $0.22 ; r=-0,15, p=0,258$ ) (Şekil 1).

\section{TARTIŞMA}

$\mathrm{Bu}$ çalışma, düzenli pilates egzersizi yapan kadınlar ile düzenli egzersiz yapmayan kadınların, YBT ölçümündeki performans farklığının olup olmadığını ortay koymak amacıyla, pilates egzersizi yapan grupta YBT uzanma ve toplam uzanma mesafesinin daha yüksek olacağı hipotezi üzerine tasarlandı. Elde edilen bulgular, çalışmanın hipotezini destekler şekilde, YBT ölçümleri sonucunda düzenli pilates egzersizi yapan kadınlarla sedanter kadınlar arasında özellikle ANT ve PM uzanma puanlarına göre anlamlı farklııklar olduğunu gösterdi.

Şekil 1. Bütün katılımcıların bacak uzunluğu VKi değerleri ile COMP uzanma mesafeleri arasındaki ilişsi $(n=62)$.
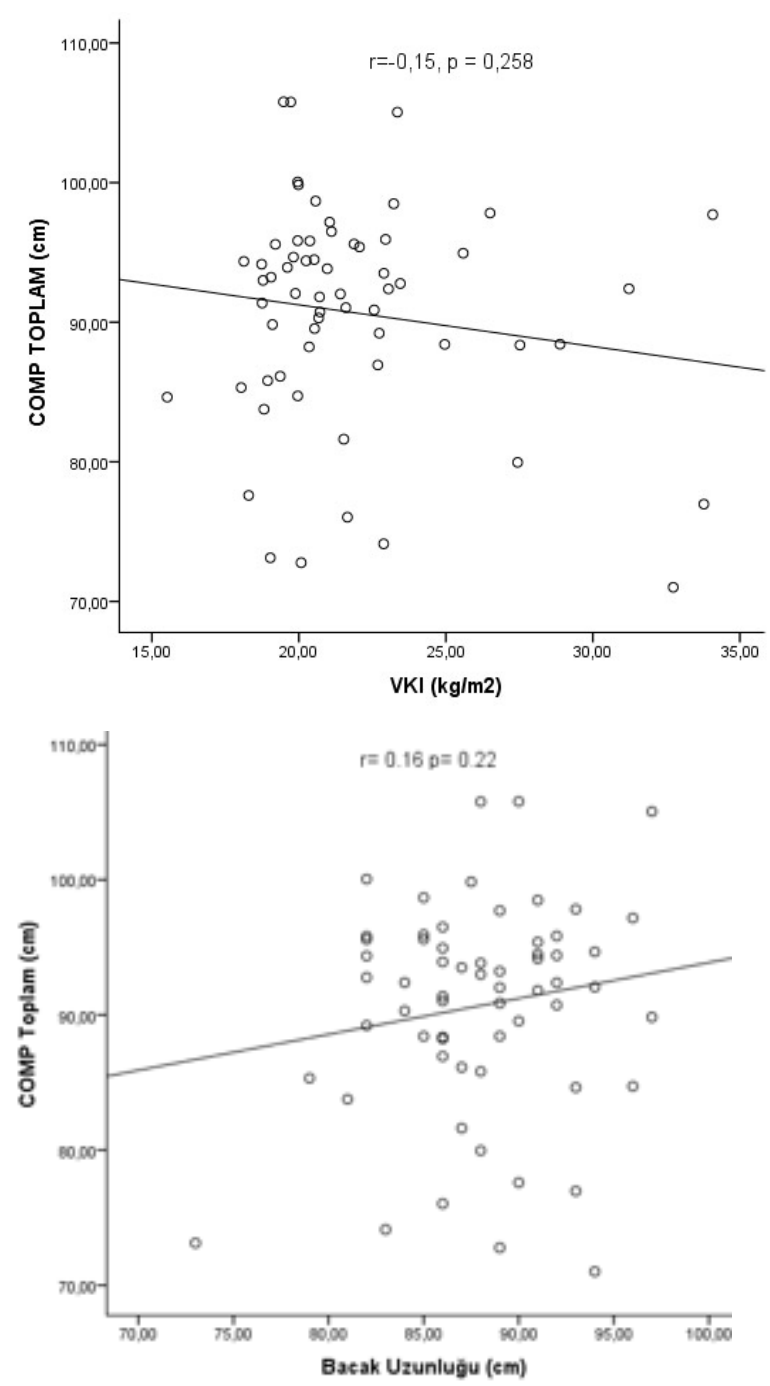

Sportif egzersizlerin branşa özgü postüral adaptasyonları geliştirdiği (15) daha önce bildirilmişti. Haksever ve ark. sağlıklı bireylerin denge parametrelerini geliştirmeyi amaçladıkları çalışmalarında YBT'nin PM ve PL parametrelerinde istatistiksel yönden anlamlı bir gelişme tespit ederken, ANT parametresinde herhangi bir anlamlı gelişme tespit edememişler ve araştırma sonucuna göre denge eğitiminin fonksiyonel testler ve tek bacak durma performansı üzerine olumlu etkileri olduğunu belirtmişlerdir (23). Thorpe ve Ebersole tarafından kadın 
futbolcularda yapılan bir çalışmada, Yıldız Denge Testi'nin antrenman yaşına göre değiştiğini ve futbol yapan üniversiteli kadınlarda, Yıldız Denge Testi (SEBT)'nin serbest zaman amaçı futbol oynayan, futbolcu olmayan kadın öğrencilere göre, anlamlı derecede daha yüksek olduğunu tespit etmişlerdir (24). Ayrıca çalışmada, kadın futbolcuların futbolcu olmayan katılımcılardan anlamlı derecede daha yüksek ekstremite kuvvetine sahip olduğunu ve ANT ve PL yönlerde önemli ölçüde daha uzağa ulaştığını göstermiştir ve bu durumun ekstremiteler yoluyla daha büyük nöromüsküler kontrol sağlanmasından olabileceği vurgulanmıştır. Ateş 12-14 yaş grubu, voleybol oynayan ve herhangi bir branşla ilgilenmeyen kız çocuklarda dinamik postüral kontrolü Yıldız Denge Testi ile değerlendirmiştir. Çalışma sonunda voleybol oynayan grupta her iki bacak PL ve COMP dinamik denge performansı skorları herhangi bir sporla ilgilenmeyen gruba göre daha yüksek bulunmuştur (2).

Freund ve ark. 50-79 yaş arası sağlıklı kadınlar üzerine yaptıkları bir çalışmada 50-59 yaş arası kadınların COMP puanlarının daha yüksek olduğunu tespit etmişlerdir (5). Araştırmamızda PG'nin sağ bacak COMP puanının KG'ye göre anlamlı farklıık olacak şekilde yüksek olduğu belirlenirken, sol bacak ve toplamda COMP puanlarının iki grup arasında herhangi bir anlamlılık oluşturmadığı gözlemlendi.

Cruz-Ferreira ve ark. pilates egzersizlerin sağlıklı bireylerde etkisini inceleyen derleme çalışmada, dinamik dengeyi geliştirmek için pilates egzersizlerinin kullanımının etkili olduğunu gösteren güçlü kanıtlar olduğunu bildirmişlerdir (25). Johnson ve ark. 5 hafta ve haftanın 7 günü 40 sağlıklı birey üzerinde uyguladıkları pilates egzersizlerinin postür, dinamik denge gibi parametrelerde olumlu gelişmelere katkıda bulunduğunu belirtmişlerdir (21).

Önceki araştırmalar, sağlıklı bireylerde SEBT performansının her iki bacakta benzer olduğunu bildirmiştir. Plisky ve ark. sağlıklı basketbolcular üzerine yaptıkları çalışma sonucunda SEBT performansı sonucu elde edilen değerlerin gelecekte oluşabilecek bacak sakatlıkları ile ilgili bilgiler verebileceğini belirtmişlerdir (14). Yapılan bu güncel çalışmanın güçlü yönlerinden biri ise, sağıklı bireylerin sağ ve sol bacak ortalama fark değerleri (OF) incelenerek ileride oluşabilecek sakatlık riskinin belirlenerek ortaya çıkabilecek risklerin önüne geçilebilecek önerilerin verilmesi olarak söylenebilir.
OF farkının $>=4 \mathrm{~cm}$ olması durumunda ileride sakatlık geçirme riskinin daha fazla olduğu çalışmalar mevcuttur (26). Araştırmamızda KG'nin ANT, PM ve PL yönlerinin OF farkları PG'ye göre daha yüksek bulundu. Özellikle PM yönü OF farkının $>4 \mathrm{~cm}(5,2 \pm 4,9)$ olarak tespit edildi. Smith ve ark. lise öğrencisi 51 erkek ve 59 kadın katılımcı ile gerçekleştirdikleri YBT performansı değerlendirmesine yönelik çalışmalarında erkeklerin \%54,9'u, kadınların ise \%50,8'inin PM yönlerinin farkını araştırmamızla paralel olarak $>4 \mathrm{~cm}$ olarak bulmuşlardır (27).

Sonuç olarak, bu çalışmanın bulguları pilates yapan sağlıklı kadınlarda YBT'nin 3 yöndeki uzanma değerleri ve toplam puanlarının sedanter gruba göre daha yüksek olduğunu göstermektedir. Bu durumda, egzersiz yapan bireylerde uygulanan YBT uygulamaları sedanter bireylere referans olarak alınmamalı. Ayrıca sedanter bireylerde YBT ile ilgili norm değerler oluşturulabilmesi için daha geniş örneklem sayıları ile daha fazla uygulama yapılması önerilmektedir.

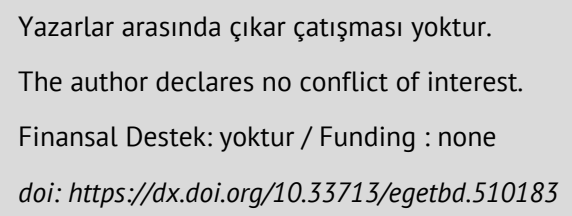

\section{KAYNAKLAR}

1. Ateş $B$, Çetin $E$, Yarım I. Kadın sporcularda denge yeteneği ve denge antrenmanları. Gaziantep Üni Spor Bil Der. 2017; 2(2):6679.

2. Ateş, B. Düzenli Spor Yapan ve Yapmayan 12-14 Yaş Grubu Kız Çocuklarda Statik ve Dinamik Denge Performansının Incelenmesi. Niğde Üni Bed Eğitimi ve Spor Bil Der. 2017; 11(1): 1-8.

3. Ringhof S, Stein T. Biomechanical assessment of dynamic balance: Specificity of different balance tests. Human Mov Sci. 2018; 58: 140-147.

4. Gribble PA, Hertel J, Plisky P. Using the Star Excursion Balance Test to assess dynamic postural-control deficits and outcomes in lower extremity injury: a literature and systematic review. J Athl Train. 2012; 47(3): 339-357.

5. Freund JE, Stetts DM, Oostindie A, Shepherd J, Vallabhajosula S. Lower Quarter Y-Balance Test in healthy women 50-79 years old. J Women \& Aging. 2018; 30(1): 1-17.

6. Lee TS, Oh JS. Relationships among the $Y$ balance test, Berg Balance Scale, and lower limb strength in middle-aged and older females. Brazilian J Phys Ther. 2015; 19(3): 227-234. 
7. Lee DK, Kim GM, Ha SM, Oh JS. Correlation of the Y-balance test with lower-limb strength of adult women. J Phys Ther Sci. 2014; 26(5): 641-643.

8. Chimera NJ, Smith CA, Warren M. Injury history, sex, and performance on the functional movement screen and $\mathrm{Y}$ balance test. J Athl Train. 2015; 50(5): 475-485.

9. O'Malley E, Murphy J, Gissane C, McCarthy-Persson U, Blake C. Effective exercise based training interventions targeting injury prevention in team-based sports: A systematic review. $\mathrm{Br}$ J Sports Med. 2014; 48: 647.

10. Butler RJ, Lehr ME, Fink ML, Kiesel KB, Plisky PJ. Dynamic balance performance and noncontact lower extremity injurying college football players: An initial study. Sports Health. 2013; 5: 417-422.

11. Huxham FE, Goldie PA, Patla AE. Theoretical considerations in balance assessment. Aust J Physiother. 2001; 47(2): 89-100.

12. Engquist KD, Smith CA, Chimera NJ, Warren. Performance comparison of student-athletes and general college students on the functional movement screen and the $Y$ balance test. J Strength Cond. Res. 2015; 29(8): 2296-2303.

13. Lehr ME, Plisky PJ, Butler RJ, Fink ML, Kiesel KB, Underwood FB. Field-expedient screening and injury risk algorithm categories as predictors of noncontact lower extremity injury. Scand J Med Sci Sports. 2013; 23(4): 225-232.

14. Plisky PJ, Rauh MJ, Kaminski TW, Underwood FB. Star Excursion Balance Test as a predictor of lower extremity injury in high school basketball players. J Ortho Sports Phys Ther. 2006; 36(12): 911-919.

15. Paillard T, Noe F, Riviere T, Marion V, Montoya R, Dupui P. Postural performance and strategy in the unipedal stance of soccer players at different levels of competition. J Athl Train. 2006; 41(2): 172.

16. Bressel E, Yonker JC, Kras J, Heath, EM. Comparison of static and dynamic balance in female collegiate soccer, basketball, and gymnastics athletes. J Athl Train. 2007; 42(1): 42.

17. Latey P. The Pilates method: history and philosophy. J Bodywork Mov Ther. 2001; 5 (4): 275-282.

18. Wells C, Kolt GS, Bialocerkowski A. Defining Pilates exercise: a systematic review. Comp Ther Med. 2012; 20 (4): 253-262.

19. Zolfaghari $N$, Faramarzi $M$, Afkhami-Ardekani $M$, Jazi, $A A$, Afkhami-Ardekani, A, Ashkezari SJ. The effect of eight weeks pilates exercise on testosterone and sexhormone biding globulin (shbg) in women with type 2 diabetes. Iranian J Diab Obesity. 2015; 7(2): 45-50.

20. Mete $S$, Milert A. Joseph Pilates' method andpossibilities of its application in physiotherapy. Med Rehabil. 2007; 11(2): 2736.

21. Johnson EG, Larsen A, Ozawa H, Wilson CA, Kennedy KL. The effects of Pilates-based exercise on dynamic balance in healthy adults. J Bodywork Mov Ther. 2007; 11(3): 238-242.

22. Gribble PA, Hertel J. Effect of hip and ankle muscle fatigue on unipedal postural control. J Electromyography Kinesio. 2004; 14(6): 641-646.
23. Haksever B, Düzgün I, Yüce D, Baltacı G. Sağlıkı Bireylerde Standart Denge Eğitiminin Dinamik, Statik Denge ve Fonksiyonellik Üzerine Etkileri. Gazi Üni Sağlık Bil Der. 2007; 2(3): 40-49.

24. Thorpe JL, Ebersole KT, Unilateral balance performance in female collegiate soccer athletes. J Strength Cond. Res. 2008; 22(5): 1429-1433.

25. Ferreria-Cruz A, Fernandes J, Laranio L, Bernardo LM, Silvia A. A systematic review of the effects of pilates method of exercise in healthy people. Arch Phys Med Rehabil. 2011; 92(12): 2071-2081.

26. Plisky PJ, Gorman PP, Butler RJ, Kiesel KB, Underwood FB, Elkins $B$. The reliability of an instrumented device for measuring components of the star excursion balance test. North American J Sports Phys Ther. 2009; 4(2): 92.

27. Smith LJ, Creps, JR, Bean R, Rodda B, Alsalaheen B. Performance and reliability of the $\mathrm{Y}$-Balance Test $^{\mathrm{TM}}$ in high school athletes. J Sports Med Phys Fitness. 2018; 58(11): 16711675. 